\title{
Prospects of Membrane Science Development
}

\author{
P. Yu. Apel ${ }^{a}$, O. V. Bobreshova ${ }^{b}$, A. V. Volkov ${ }^{c}$, V. V. Volkov ${ }^{c}$, V. V. Nikonenko ${ }^{d}$, \\ I. A. Stenina ${ }^{e}$, A. N. Filippov $f$, Yu. P. Yampolskiic ${ }^{i}$ and A. B. Yaroslavtsev ${ }^{c, e, *}$ \\ ${ }^{a}$ Joint Institute for Nuclear Research, Dubna, Moscow oblast, 141980 Russia \\ ${ }^{b}$ Voronezh State University, Voronezh, 394018 Russia \\ ${ }^{c}$ Topchiev Institute of Petrochemical Synthesis, Russian Academy of Sciences, Moscow, 119991 Russia \\ ${ }^{d}$ Kuban State University, Krasnodar, 350040 Russia \\ ${ }^{e}$ Kurnakov Institute of General and Inorganic Chemistry, Russian Academy of Sciences, Moscow, 119991 Russia \\ ${ }^{f}$ Gubkin Russian State University of Oil and Gas (National Research University), Moscow, 119991 Russia \\ *e-mail: yaroslav@igic.ras.ru \\ Received October 12, 2018; revised November 22, 2018; accepted December 4, 2018
}

\begin{abstract}
Membranes are widely used in modern technology. The demand for different types of membranes and membrane processes is increasing every year. This review summarizes the current state of the art and prospects of membrane science developments including membrane materials for gas separation, pervaporation, and pressure-driven membrane processes; ion-exchange, hybrid, and track-etched membranes; membranes for electrochemical sensors; and mathematical modeling of membrane separation processes and ion and water transport in membrane systems. Studies aimed at improving the selectivity and performance of membranes and their stability are surveyed. New approaches to the synthesis and modification of membranes as well as their advanced applications are discussed.
\end{abstract}

Keywords: membranes, gas separation, ion-exchange membranes, hybrid membranes, track-etched membranes, sensors, pervaporation, pressure-driven membrane processes, mathematical modeling

DOI: $10.1134 / \mathrm{S} 2517751619020021$

\section{INTRODUCTION}

Membrane science is widely sought after by modern technologies. Membranes are traditionally used for executing the processes of separation, purification, and concentration of gaseous and liquid media. At the same time, research in the field of application of membranes in alternative energy, sensorics, biology and medicine, and membrane catalysis and for solving a series of other applied tasks is being actively carried out. Various hybrid technologies, in which membrane technologies are used at one or several stages, develop as well. In this regard, the demand for various membranes and membrane processes broadens year by year. Different types of membranes, to which a specific set of requirements is imposed, turn out to be sought after for different processes. Nevertheless, some similarity can be noted in them. In recent years, interest in obtaining new types of membranes that are distinguished by high productivity and selectivity has significantly increased [1-4]. Mechanical strength, chemical stability, elasticity, and cost should be noted among other important parameters. Considerable attention has been paid to studies on membrane fouling as a result of blocking of the surface or clogging membrane pores by solution components, precipitate being formed, and growth of bacteria or algae. This list of problems can be substantially expanded.

The tasks facing scientists who work in the field of membrane science are distinguished by enviable diversity, and it is quite difficult to trace all the aspects of the development of this field. The journal Membranes and Membrane Technologies annually publishes a whole range of original works and reviews devoted to the synthesis and investigation of new types of membranes, development of the processes of membrane separation and purification, and use of membranes in many other fields. Since 2019, the journal will be published under this name in English. In this regard, we decided to share our thoughts on the prospects of the development of different areas of membrane science are summarized in this review. Each section is composed by a scientist who is active in the corresponding research area. The sections have been prepared by the following authors in the order of presentation: Yu.P. Yampolskii, A.B. Yaroslavtsev, I.A. Stenina, O.V. Bobreshova, P.Yu. Apel, A.N. Filippov, V.V. Niko-nenko, V.V. Volkov, and A.V. Volkov. However, this review paper cannot describe all the membrane applications. Nevertheless, we hope that this review will provide a guidline to the readers in the rapidly growing world of membranes and membrane technologies. 


\section{GAS SEPARATION MEMBRANES}

One of the key applications of membrane technologies is gas separation, some advances of which can be found in recent reviews $[1,2,5,6]$. In the field of membrane gas separation, important events took place after the appearance of the first polymer with internal microporosity [7]. After this, a whole series of socalled ladder polymers with related structures was synthesized and studied. The structure and transport properties of some of them are presented in Table 1. An outstanding characteristic feature of these polymers which provided a breakthrough is associated with the fact that they are distinguished by a favorable combination of permeability and selectivity of gas separation.

For many of ladder polymers with internal microporosity, the points in the permeability-selectivity plots (so-called Robeson diagrams) are located above the "upper bounds," i.e., increased selectivity of gas separation is characteristic for these polymers. Polymers with internal microporosity can be successfully used as matrices for hybrid membranes containing nanoparticles [9]. Such polymers have a lot in common with other highly permeable materials. In particular, a large free volume was found in them by positron annihilation lifetime spectroscopy $[8,10]$. The treatment with lower alcohols (methanol and ethanol) leads to a noticeable growth in gas permeability, often without a loss of selectivity [10, 12]. Like disubstituted polyacetylenes, they show propensity to physical aging, i.e., a decrease in gas permeability over time [14]. Recently, approaches to overcome this undesirable effect have been under development [15].

One of the important tasks that have been attracting the attention of researchers in the recent years is the recovery of helium, the demand for which is extremely high, from natural gas. The difficulty consists in the fact that the concentration of helium in natural gases is generally very low, so that membranes with high selectivity are required. The best results were obtained with perfluorinated polymers as the membrane material. It was shown [16] that in the 1991 Robeson plot, perfluorinated polymers form a separate group of points that lie above the upper bound. Table 2 presents some results of the studies of new membrane materials for the separation of $\mathrm{He} / \mathrm{CH}_{4}$ mixtures obtained in recent years. The coefficient of permeability $P(\mathrm{He})$ varies in a wide range depending on the polymer structure. The selectivity $\alpha\left(\mathrm{He} / \mathrm{CH}_{4}\right)$ substantially changes as well, and more permeable polymers turn out to be less selective.

Another still not fully solved task of membrane gas separation concerning the processing of natural and associated petroleum gases is the separation of $\mathrm{C}_{1}-\mathrm{C}_{4}$ gaseous alkanes (Table 3 ). It was originally believed that only rubbers were suitable for its solution. Later, it turned out that highly permeable polyacetylenes are also more permeable to butane as compared with methane [21]. In recent years, the range of membrane materials that can be used for the solution of this task has significantly broadened. It was shown [20] that additive polynorbornenes and polytricyclononenes with $-\mathrm{SiMe}_{3}$ side groups show high gas permeability and thermodynamic selectivity.

An interesting new class of promising membrane materials has been discovered in recent years [25-27]. These are glassy polymers with flexible $\mathrm{Si}-\mathrm{O}-\mathrm{Si}$ or $\mathrm{Si}-\mathrm{O}-\mathrm{C}$ bonds in the side groups. These polymers combine the properties of glassy materials (glass transition points in the range of $100-345^{\circ} \mathrm{C}$ ) and rubbers, which is due to the local properties of flexible side groups (Table 3). Recently, similar properties have also been found in membranes on the basis of ionic liquids [28].

Inorganic membranes are worth to be noted separately. Membranes on the basis of anodic alumina (containing a through system of ordered nanopores) make it possible to separate vapors of $\mathrm{C}_{3+}$ hydrocarbons which are capable of capillary condensation from methane $[29,30]$. Thus, such membranes can be used for the separation of associated petroleum gases. As it was shown in [31], composite membranes on the basis of an individual ZIF complex supported on porous alumina are superior to polymer membranes in the process of separation of mixtures of propylene and propane [32].

\section{ION-EXCHANGE MEMBRANES: A WAY TO INCREASING SELECTIVITY}

Electromembrane processes are characterized by high diversity in their applications. Water purification and concentration, electrochemical synthesis, electrolysis, and catalysis can be distinguished among them. Ion-exchange membranes play a pivotal role in sensors, power sources (fuel cells, redox batteries, reverse electrodialysis devices, and lithium-ion batteries) [2, 3, $33,34]$. Different requirements are imposed on the membranes used in all these systems. However, there are also general requirements, among which high ionic conductivity and selectivity of transport processes can be noted. In addition, mechanical properties and cost of the membranes are important parameters.

The structure of ion-exchange membranes is generally described by the well-known Gierke model created on the basis of consideration of perfluorinated membranes. Due to the self-organization processes, hydrophobic polymer chains form the membrane matrix, while hydrophilic functional groups form a system of pores and channels by absorbing moisture from the environment. In the case of, e.g., cation-exchange membranes, the walls of these pores become covered with fixed ions (e.g., $-\mathrm{SO}_{3}^{-}$) formed via the dissociation of functional groups and the pore contains an aqueous solution with positively charged counterions $[35,36]$. For perfluorinated Nafion membranes in the hydrogen form in contact with an aqueous solution, 
PROSPECTS OF MEMBRANE SCIENCE DEVELOPMENT

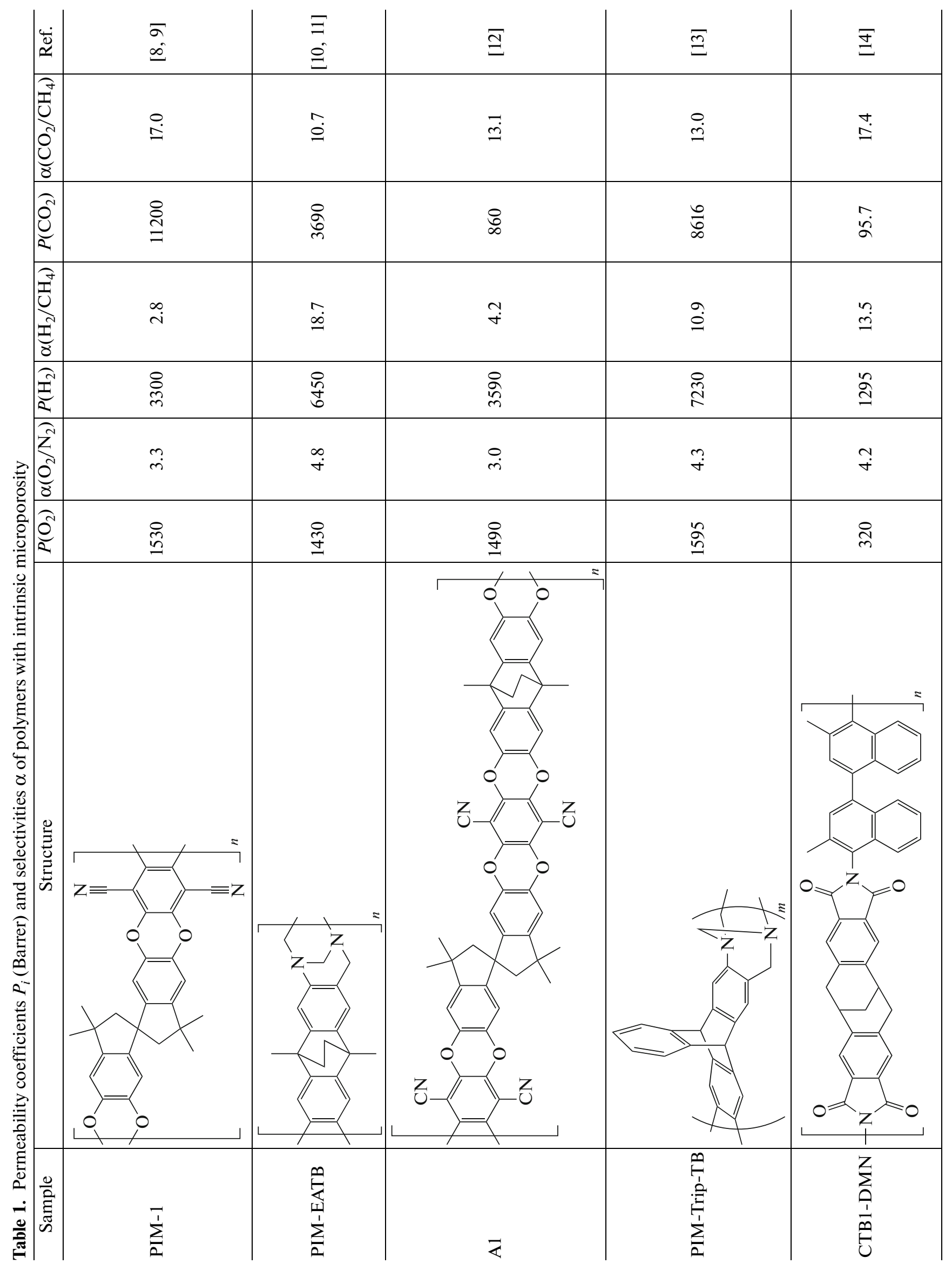


Table 2. Helium permeability coefficients (Barrer) and gas separation selectivities of perfluorinated polymers

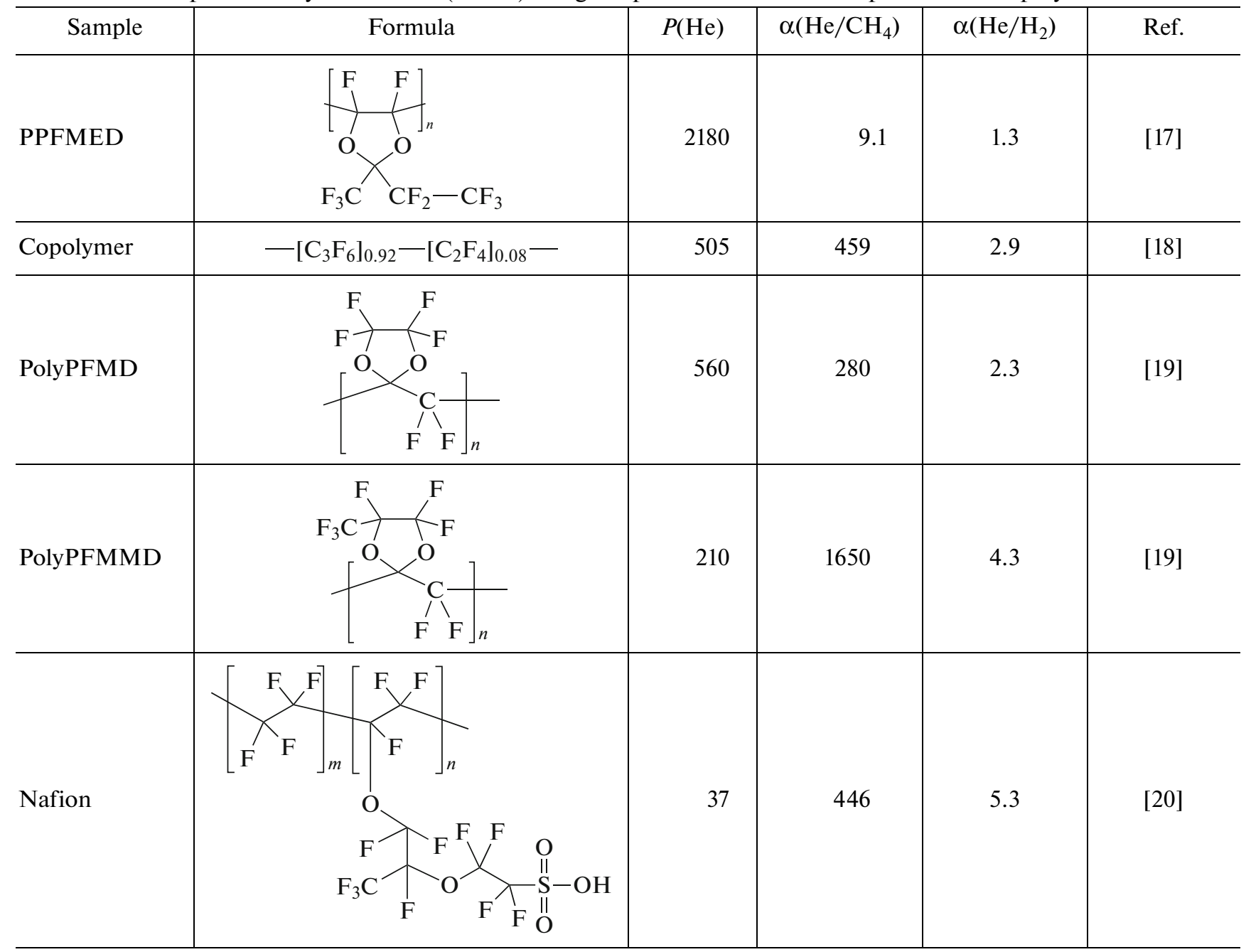

the pore size is $4-5 \mathrm{~nm}$ [37], with a large part of counterions being in the Debye layer with a thickness of about $1 \mathrm{~nm}$ localized near the pore walls of the membranes. It is the transport in this layer that determines the ionic conductivity of the membranes. The higher the acidity and concentration of functional groups, the higher the concentration of charge carriers and conductivity of the membranes. The remaining pore volume is filled with an electroneutral solution, the composition of which is close to that of the solution surrounding the membrane [38]. It is important to note that a low concentration of coions or gas molecules relative to that of counterions governs their transport through the membrane, thereby determining its incomplete selectivity. Indeed, for use in different applications, it is important to decrease the transport of particles of different types (for electrodialysis, these are coions that have a charge of the same type as the fixed ions; for fuel cells, the transport of the fuel and oxidant (hydrogen, oxygen, and methanol) molecules), but the nature of the decrease in selectivity is general for these processes [39]. Although, strictly speaking, a different mechanism of gas transport in membranes of this type-through the polymer matrix-is also possible.

It is noteworthy that an increase in the water uptake of membranes leads to a growth in the size of pores and pore-connecting channels; their size controls ionic conductivity [38]. However, the volume of the electroneutral solution localized in the center of the pores increases simultaneously. Because of this, all other conditions being equal, an increase in the ionic conductivity of membranes should be accompanied by a decrease in their selectivity, a behavior that is confirmed by statistical data for various membranes plotted on a general diagram similar to the Robeson plot for gas separation (Fig. 1) [40].

It is seen from the presented data that homogeneous membranes have a significant advantage over heterogeneous membranes. This is determined by the fact that heterogeneous membranes are generally obtained by rolling or pressing of an ion-exchange resin and a plasticizer. In this connection, the contact between their particles is not optimum, and such 
Table 3. Coefficients of permeability $P\left(\mathrm{C}_{4} \mathrm{H}_{10}\right)$ (Barrer) and gas separation selectivities of polymers

\begin{tabular}{l|c|c|c}
\hline Structure & $P\left(\mathrm{C}_{4} \mathrm{H}_{10}\right)$ & $\alpha\left(\mathrm{C}_{4} \mathrm{H}_{10} / \mathrm{CH}_{4}\right)$ & Ref. \\
\hline
\end{tabular}

membranes are characterized by a bimodal pore size distribution [41]. The presence of large pores (of about $10^{3} \mathrm{~nm}$ ) determines the lower selectivity of transport processes. From this viewpoint, the use of grafted membranes obtained via graft polymerization of styrene in dense polymer films activated by ionizing or UV radiation followed by sulfonation appears to be very promising. In composition, such membranes are almost identical to heterogeneous membranes, but the absence of secondary porosity makes them much more selective [42, 43]. An alternative method, in which membranes are activated by their mechanical stretching, is being developed as well. Membranes on the basis of polyvinylidene fluoride were obtained in this manner [44]. The wide possibility for varying the ion-exchange capacity and water uptake of grafted membranes by varying the degree of grafting and crosslinking makes it possible to obtain membranes with unexpected properties. Thus, in membranes with a water uptake significantly exceeding that of Nafion membranes, it turned out to be possible to experimentally show the presence of a fraction of almost pure water in the center of the pores [45].

It should be noted that the selectivity of ionexchange membranes has been a vigorously debating issue in recent years, including discussions in review papers $[3,4,46,47]$. Here, particular attention is paid to the selective separation of ions of like charge, especially singly and doubly charged ions. This is due to the fact that selective electrodialysis started being widely used for the removal of multicharged ions from solutions, production of lithium and sodium salts from seawater, as well as adjustment of acidity of wines and dairy products and concentration of harmful singly charged cations in water [4, 47-49]. The mechanism of selective transport of ions through membranes is most often determined by their affinity to the membranes of this type (the equilibrium constant of the exchange) and ion mobility in the membrane (the ratio of the mobility of ions) [50]. In general case, the mobility of doubly charged ions is increased by the stronger Coulomb attraction to the electrodes, but is decreased by stronger binding. The Stokes radius should play an important role. As a result of the interplay of these effects, quite unconventional series of the change in the selectivity of the transport through cation-exchange $\left(\mathrm{Ba}^{2+}>\mathrm{Sr}^{2+}>\right.$ $\left.\mathrm{Ca}^{2+}>\mathrm{Mg}^{2+}>\mathrm{H}^{+}>\left(\mathrm{Cu}^{2+} \sim \mathrm{Zn}^{2+} \sim \mathrm{Ni}^{2+}\right)>\mathrm{K}^{+}\right)[4]$ and anion-exchange $\left(\mathrm{I}^{-}>\left(\mathrm{NO}_{3}^{-} \sim \mathrm{Br}^{-}\right)>\mathrm{NO}_{2}^{-}>\mathrm{Cl}^{-}>\right.$ $\mathrm{SO}_{4}^{2-}>\mathrm{F}^{-}$) membranes are obtained [51].

An approach based on the modification of the membrane surface often turns out to be very produc- 


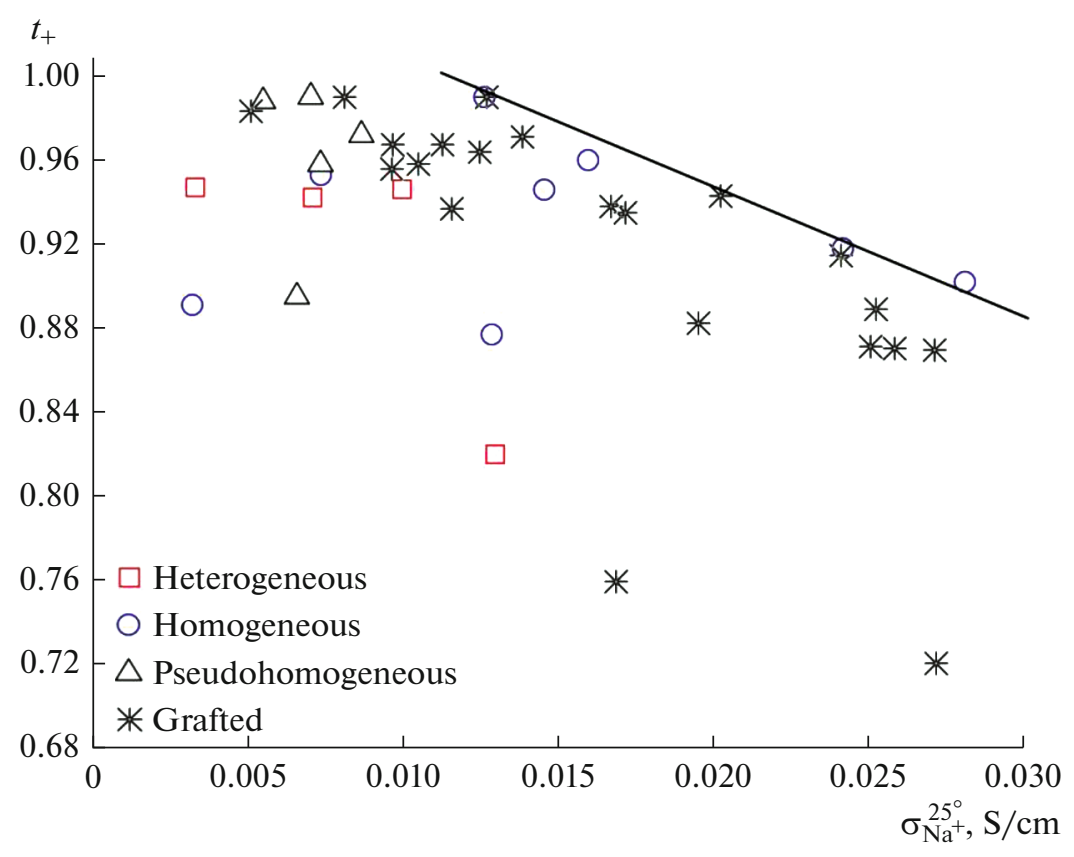

Fig. 1. Dependence of the potentiometric transport numbers of sodium ions $(0.5 \mathrm{M} / 0.1 \mathrm{M} \mathrm{NaCl})$ on their ionic conductivity in the $\mathrm{Na}^{+}$form $(0.5 \mathrm{M} \mathrm{NaCl})$ for a number of ion-exchange membranes including homogeneous, heterogeneous, pseudohomogeneous, and grafted membranes (by data from [40]).

tive. Various researchers examined the effects associated with the application of a layer of a more selective homogenous membrane and hydrophobization or hydrophilization of the surface [4]. It turned out to be possible to substantially increase the selectivity of the transport of singly charged ions by introducing amorphous zirconium phosphate, which possesses high affinity to multicharged ions, into the surface layer of a heterogeneous membrane [52]. Krasemann and Tieke [53] proposed a method for creating high selectivity of membranes by applying thin layers of polyelectrolytes with alternating charge signs of the fixed groups. This method turned out to be very productive and was widely used by some researchers for making relatively cheap, highly selective membranes on the basis of various heterogeneous materials. For example., Zhao and coworkers [54, 55] fabricated an anion-exchange membrane on the basis of a commercial sample, onto which sodium polystyrene sulfonate and hydroxypropyltrimethylammonium chloride chitosan were electrolytically deposited. As a result, a high-performance electrodialysis membrane with the possibility of separation of singly and doubly charged anions was obtained. Cation-exchange membranes are obtained in a similar manner as well $[56,57]$.

This line of research can be considered as one of the most promising. However, the cause of the effect of high charge selectivity has not been completely disclosed, so that both experimental and theoretical studies on this issue are required.

\section{HYBRID MEMBRANES: A WAY TO IMPROVING PROPERTIES}

The membranes should possess a combination of required properties to be implemented in a certain device. However, the limited number of commercially available membranes often does not allow to meet these criteria. It often turns out to be necessary to improve one or several parameters. In this case, methods associated with the modification of membrane materials are used. The creation of hybrid membranes which emerged in the late 1980s became one of the most actively developing approaches and almost immediately became sought for by the scientific community $[31,58]$. It is quite unexpected that works in this direction developed almost synchronously for the improvement of both ion-exchange membranes which is determined by the prospects for their use in fuel cells [59] and gas-separation membranes that are often named mixed matrix membranes in the Englishspeaking scientific community [60]. Despite the fact that the transport processes in ion-exchange and gasdiffusion membranes proceed according to different mechanisms, the properties of these membranes change similarly in the case of introduction of nanoparticles of inorganic compounds into them [61].

When modifying ion-exchange membranes, the attention of researchers is usually attracted by the possibility for increasing their proton conductivity which is generally implemented only for a low dopant concentration. To explain this phenomenon, a model of "limited elasticity of membrane pore walls" was pro- 
posed, under which the intercalation of a dopant into the membrane pores leads to their widening together with the widening of the channels that control the membrane conductivity [62]. The water uptake of the membranes should remain almost unchanged or can somewhat increase due to the additional sorption of water on the surface of hydrophilic dopants. Due to the increase in the total pore size, the size of channels connecting them grows as well. As a result, an enhancement of proton transport through narrow channels and overall permeability of the membranes is observed. At a dopant concentration increased above 2 vol \%, osmotic pressure becomes insufficient for overcoming the elastic forces of deformation of the material; as a result, the water uptake of the membranes and their conductivity decrease [62].

The possibility for maintaining high proton conductivity at a low humidity of the environment, when the conductivity of common membranes decreases by several orders of magnitude due to the dehydration and decrease in the volume of pores and channels, is an important advantage of hybrid membranes. An increase in conductivity at reduced humidity can be achieved by incorporating dopants that a surface with pronounced acidic properties, e.g., heteropoly acids or their acidic salts, into membranes [63, 64]. This is especially important for application in fuel cells, the capacity of which at low humidity can be increased by using membranes containing zirconium phosphate or salts of heteropoly acids [65]. The reason for the increase in the conductivity of membranes at low humidity is the prevention of the excessive narrowing of the pores at reduced humidity and, as a consequence, the increase in the size of pore-connecting channels. In addition, the dopant surface can actively participate in transport processes at low humidity [39].

It has been noted above that one of the important properties of membranes is their selectivity. A decrease in the transport numbers of coions was reported for a number of hybrid ion-exchange membranes $[64,66]$. From the viewpoint of application of hybrid membranes in fuel cells, an extremely important aspect is to reduce the transport of methanol and gas molecules by inherent diffusion across the membrane (crossover) $[67,68]$. As noted above, their transport processes primarily occur in the electroneutral aqueous solution localized in the center of membrane pores. The formation of nanoparticles in membrane pores leads to the displacement of the electroneutral solution from the center of the pores in the first place. On the contrary, the conductivity of membranes is determined by the transport of counterions in the Debye layer along the pore walls [39]. As a result, the transport of coions and neutral molecules in hybrid membranes becomes complicated, whereas their ionic conductivity more frequently changes little or increases.

The creation of hybrid membranes by incorporating nanoparticles with a modified surface can be con- sidered very promising. First of all, imparting acidic properties to them is of interest. Nafion membranes containing silica nanoparticles with grafted sulfo groups or sulfonic acid fragments [69, 70] exhibited increased proton conductivity and low methanol permeability. It turned out to be possible to substantially decrease the methanol permeability by doping Nafion membranes with metal oxides, silica, and phosphotungstic acid [71, 72]. The modification of membranes by sulfonated zeolites made it possible to decrease methanol permeability, keeping the proton conductivity unchanged, and to significantly increase the power density of methanol fuel cells [73]. The creation of an additional electrical double layer near the surface of nanoparticles with acidic properties leads to an additional displacement of coions and low-polarity molecules from membrane pores and improvement in transport selectivity. On the other hand, the selectivity can sometimes be enhanced by modifying silica with hydrocarbon moieties containing basic nitrogen atoms [74] due to their binding with the pore walls and the decrease in the volume of the interstitial solution.

In general, introducing inorganic particles into polymer matrices leads to a decrease in the diffusion and permeability coefficients of gases according to the Maxwell model. However, on the opposite, introducing nanosized particles into glassy and rubbery polymers leads to a growth in the gas permeability as a result of creation of the porosity at the interfaces [9]. For matrices on the basis of a polymer with intrinsic microporosity (PIM-1) [75], a growth in the permeability accompanied by a decrease in the separation factors was observed.

However, the incorporation of carbon nanotubes (CNTs) turned out to be more productive, since the transport through CNT channels is also possible. In the presence of functionalized CNTs, the permeability coefficients of gases in the systems based on the PIM-1 polymer with intrinsic microporosity increase already at low concentrations of the additive [76]. Significant expectations are laid on the possibility for the "sieve gas separation" using zeolites. Thus, introducing zeolites into a polyethersulfone matrix led to an increase in the permeability and the $\mathrm{H}_{2} / \mathrm{CH}_{4}$ and $\mathrm{H}_{2} / \mathrm{CO}_{2}$ separation selectivities [77]. In some cases, researchers manage to overcome the Robeson limit, for example, by incorporating the $\mathrm{Nu}-6$ (2) zeolite into copolyimide [78]. Metal-organic frameworks (MOFs) are also used as components of hybrid composite membranes [9, 31].

The data presented in this section show the possibility for the wide practical application of hybrid membranes for designing fuel cells and gas separation processes. Their possible use in advanced water treatment processes [79] and sensor systems [80] has also been reported. 


\section{MEMBRANES FOR ELECTROCHEMICAL SENSORS}

The development of state-of-the-art rapid analysis methods is first of all associated with the design and systematic investigation of new materials for chemical sensors. Potentiometric and voltammetric sensors on the basis of ion-exchange membranes became the most widespread. Since the number of commercial membranes is very limited, the efforts of researchers are aimed at improving their properties.

Polyvinyl chloride (PVC) membranes are most often used in electrochemical sensors [81, 82]. When developing sensors on their basis, in addition to the choice of the active components providing the response to the analyte (or a set of analytes), the selection of plasticizers that act as solvents for the active components and provide the elastic properties of the polymer with a high glass transition point is important [81]. Ionophores, neutral or charged lipophilic compounds that act as ligands in the complexation reaction with analyte ions, are the most commonly used as the active components of selective sensors [82]. Ion exchangers (salts of tetraphenylboric acid derivatives and quaternary ammonium salts (alkyl sulfates) with the alkyl chain length of no less than eight [83]) including ion exchangers initially developed for liquid extraction (chlorinated cobalt dicarbollide and sodium di(2-ethylhexyl)sulfosuccinate [84]) become the active components for cross-sensitive sensors. Despite the fact that sensors on the basis of PVC membranes predominate among commercial devices, the problem of their stability due to the low adhesion of PVC to the surface of a transducer (in solid-contact sensors) and leaching of the insufficiently lipophilic components of membranes (plasticizers in the first place) remains unsolved. To eliminate leaching, the replacement of PVC membranes by self-plasticized acrylic and methacrylic membranes and the replacement of low-molecular weight plasticizers by their polymeric analogues are proposed [81]. For the same purpose, ionophores that are chemically bound to the membrane matrix or nanoparticles intercalated into it are used [85]. To increase the adhesion of the sensitive layer of solid-contact sensors, polymers obtained via the electropolymerization directly on the electrode surface, into which active components can be introduced later, are used. Polyaniline [86], polypyrrole [87, 88], and polythiophenes [88] with electron-ion conductivity, the morphology and properties of which are varied by means of controlling the electrochemical parameters of the synthesis, appear to be the most promising for these purposes.

The recent advances in the field of preparation and investigation of organic-inorganic hybrid membranes determined the growth in the number of works devoted to their use in sensorics [85, 88-90]. When creating electrochemical sensors, nanomaterials are introduced into PVC membranes [91], perfluorinated sulfonic cation-exchange materials of the Nafion type [89], polypyrrole [88], polythiophenes [88, 89], polyaniline [89], polyphenazines [90], and graphene [89]. The obtained composites are applied onto the surface of glassy carbon, paste, metallic, and graphite electrodes.

The modification of voltammetric sensors (by carbon nanotubes and nanofibers [92] and nanoparticles of metals and inorganic oxides [93]) is aimed at decreasing the overvoltage of the electrode reaction, increasing the analyte sorption on the electrode, as well as increasing the selectivity and electrocatalytic activity to the analyte, stability, and service life of the sensors. The determination of hormones and drug substances in biological fluids and tissues for clinical diagnostics; determination of antioxidants, flavor enhancers, and aromatic compounds in food products; and determination of surfactants and transition metal ions in natural and drinking water and sewages can be distinguished as the main tasks solved using voltammetric sensors on the basis of hybrid membranes.

When creating potentiometric solid-contact sensors, polymer films containing carbon nanomaterials (CNTs, fullerenes, macroporous carbon, and graphene and its oxides) [85] or Nafion (as a molecular dopant) [94] increase the adhesion to the electrode surface, serve as ion-electron converters that increase the capacity of the electrical double layer at the interface between the electronic conductor and ion-selective membrane, as well as prevent the penetration of the solution between them. The use of Nafion in the form of films in such sensors prevents the sorption of redox-active compounds (e.g., ascorbate ions) that poison the electron conductor material [95]. Potentiometric solid-contact sensors on the basis of hybrid membranes for the determination of alkaline and transition metal ions and hydrogen peroxide are the most commonly used.

The possibilities for the use of hybrid materials in potentiometric sensors with an internal reference solution have not been implemented so far. This is associated with the need for the development of individual approaches to the fixation of new materials in the sensor sheath and elimination of transmembrane fluxes from the reference solution. In [80, 96-99], for minimizing the ion fluxes through a membrane, it is proposed to substantially increase the distance between its boundaries with the reference and test solutions, due to which the response is determined by the Donnan potential (DP) at the boundary of the membrane with the test solution. This allows using perfluorinated sulfonic cation-exchange membranes (Nafion and MF-4SK) that are gradient-modified along the length in DP sensors for the determination of amino acids, vitamins, and drugs. DP sensors do not contain components that selectively interact with the analytes and are cross-sensitive to organic and inorganic ions. Varying the characteristics of mem- 
branes for the optimization of the analytical signal is achieved by means of introducing nanoparticles of dopants and treatment using physicochemical methods. Hydrated inorganic oxides including those surface-modified by sulfur- [96] and nitrogen-containing $[80,97]$ and hydrophobic hydrocarbon moieties [97], as well as acidic salts of heteropoly acids [98], are used as the dopants. The properties of membranes were also altered by thermal treatment at different humidities or using mechanical deformation [99]. The value of the response is determined by the processes of exchange and nonexchange sorption which occur upon the establishment of quasi-equilibrium at the membrane interface with the test solution. Increasing the number of sorption sites and selectivity of the membranes makes it possible to increase the accuracy and sensitivity of the determination of organic cations and zwitterions at $\mathrm{pH}<7$ and to decrease their detection limits [97-99]. At a low volume of the solution in the pores of hybrid membranes, the concentration of analyte ions in them turns out to be high, and their interaction with the functional groups of the membrane excludes some protons from the ion exchange, thus decreasing the influence of interfering ions on the response of the sensor. A nontrivial result is achieved in the case of using membranes with increased diffusion permeability and low water uptake in DP sensors. This provides a high sensitivity of DP sensors simultaneously to counterions and coions in a wide $\mathrm{pH}$ range and is used for the joint determination of both amino acid and drug anions and alkali metal cations [80, 96]. The investigation of the dependences of the characteristics of DP sensors on the composition and properties of membranes makes it possible to deeper understand the mechanisms of formation of the response and to develop techniques for the preparation of sensor materials with desired properties.

The prospects for the development of new sensor membrane materials and expansion of the range of substances determined with their use are associated with the preparation of membranes with controlled properties, investigation of the mechanisms of their interaction with analytes, and study of the interrelations of the structural and physicochemical properties of the membranes with the characteristics of sensors on their basis.

\section{TRACK-ETCHED MEMBRANES}

Track-etched membranes hold a special place in the area of membranes and membrane technologies. The analysis of the literature shows a sharp growth in the publication activity on track-etched membranes, the beginning of which dates back to the mid-1990s [100]. To the traditional fields of application of tracketched membranes (TMs)-use in chemical, biochemical, bacteriological, and microbiological analysis; environmental monitoring; medicine; and pharmaceutics [101] — fast growing areas associated with the development of nanofluidics, sensorics, and life sciences have been added. Research-and-development works in these fields require the use of microand nanopores with predetermined geometry and surface properties [102-107]. Significant progress in these works was achieved in particular due to the unique procedure for fabrication of membranes with a single track-etched pore [108]. Together with the expansion of the research front, where the "tracketched" pores play a role of a precision tool, the search for new industrial applications of track membranes remains relevant. Thus, the experience of Russian researches showed that TMs can successfully serve for the pretreatment of aqueous media. The high performance of spiral-wound recoverable microfiltration modules as part of desalting plants was shown [109]. However, their use is limited by a high cost of the filter element. The main fields of application of TMs are where a membrane provides the preparation of an expensive desired product or allows reaching a unique effect and, because of this, its cost does not play a pivotal role.

An interesting effect is the ion current rectification by asymmetric nanopores (diode effect) [101, 110-112]. In electrolyte solutions, asymmetric "track-etched" nanopores possess a predominant direction of ion transport, which makes them similar to biological ion channels [101, 113]. In the last decade, a wealth of research was performed for the purpose of understanding the mechanism and theoretically describing the nature of the diode effect [114]. Membranes with asymmetric, in particular, cone-shaped nanopores are promising for electric power generation using reverse electrodialysis [103, 107].

Hundreds of publications are devoted to molecular sensors on the basis of membranes with single asymmetric pores. Such sensors operate based on the resistive pulse principle or molecular recognition principle [104, 107, 113-116]. The resistive pulse detection method is based on the fact that a particle, e.g., a macromolecule, passing through an orifice replaces some solution from the sensitive zone and sharply changes the electric resistance of the pore. The resistive pulse method itself is insufficiently selective if a particular molecule needs to be "recognized" and, because of this, it requires the use of a highly selective agent that has affinity to the analyte. The agent can be added to the solution being analyzed or can be covalently bound to the internal surface of the pore in the entrance zone. Carboxyl groups on the pore walls are generally used for its grafting. The applicability of the molecular recognition method with the use of asymmetric pores in the membranes made of polyethylene terephthalate and polyimide was demonstrated in a large number of original works (see, e.g., [113, 115, 116]) and reviews [104, 106, 107, 118]. "Nanopore" sensors for various protein molecules, glucose, metal ions, toxins, and narcotics were proposed. 


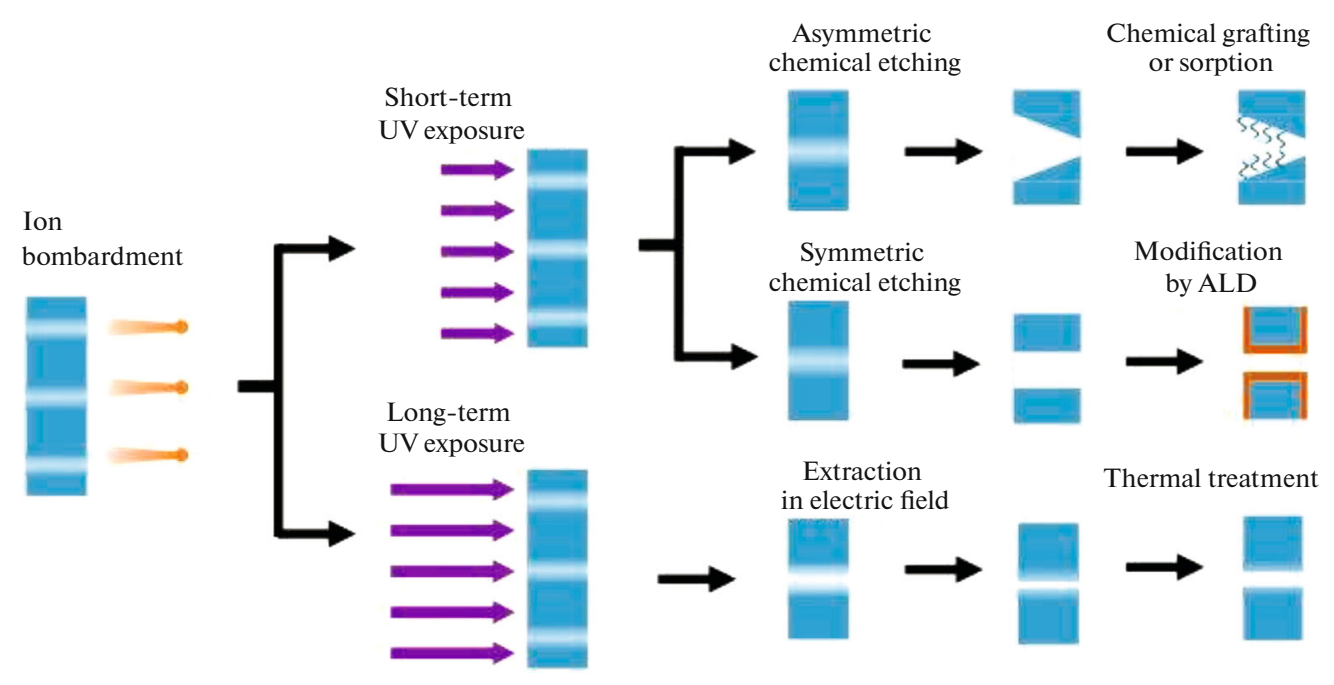

Fig. 2. State-of-the-art approaches to the formation of functional nanoporous track-etched membranes (reproduced from [117]).

Track-etched nanopores with a diode effect are also considered as functional elements in nanofluidics. Thus, they can serve as ion pumps as well as logic elements [103, 107, 117]. Grafting DNA oligomers in the pore entrance made it possible to obtain an electromechanical nanovalve that opens and closes depending on the potential difference applied to the membrane and the $\mathrm{pH}[101,107,118]$. The possibility for the creation of nanovalves controlled by magnetic field, light, and introduction of specific ions to a solution was shown [107, 119]. In this connection, various methods for modification of the pore surface gained special significance [101, 105-107]. The emergence of new useful properties or enhancement of the existing properties in membranes is achieved by grafting certain functional groups onto the surface or by sorption of polyelectrolyte layers. The use of atomic layer deposition (ALD) provides "intricate" controlling of the properties of pores of a 1-10 nm diameter. Together with the stepwise, by fraction of nanometer, change in the pore diameter, ALD makes it possible to fully change the physicochemical properties of the pore walls, namely, the electric charge sign, hydrophilicity/hydrophobicity, etc. [120]. The main state-of-the-art approaches to the formation of functional track membranes are illustrated by the scheme presented in Fig. 2. Specific transport properties, predominantly in the nanometer range of sizes, are achieved by combining several techniques, namely, UV irradiation, symmetric or asymmetric etching, and chemical and physical modification.

Track-etched membranes that are at the same time substrates for surface-enhanced Raman scattering (SERS) sensors should be considered promising hybrid devices [121, 122]. The combination of the membrane and SERS sensor functions provides the concentration of a specimen, its purification from admixtures, and the actual highly sensitive detection of the sought component by its Raman spectrum.
Track-etched membranes are widely used as templates for the synthesis of nanostructured objectsnanowires and nanotubes with high aspect and surface area/volume ratios [123]. They serve as unique models in the studies of the fundamental physical propertiesmechanical, electrical, magnetic, and thermoelectrical-depending on the size, geometry, composition, and crystal structure of the nanoscale object.

Studies aimed at creating of proton-conducting membranes on the basis of films, mainly fluoropolymeric, modified by irradiating with energetic heavy ion beams are underway. A proton-conducting polymer is grafted directly into tracks or the pores obtained by their etching [105]. Mechanically strong anisotropic membranes with performance characteristics close to those of Nafion have been developed.

The modification of a polyethylene terephthalate film with accelerated ion beams followed by long-term exposure to ultraviolet light and extraction of the radiolysis and photolysis products from the tracks forms an array of uniform pores with an effective diameter of $0.3-1 \mathrm{~nm}$ [124]. The obtained membranes show high cation selectivity in the electrodialysis mode. In that case, the transport of univalent cations is two orders of magnitude faster than that of divalent cations at a high productivity. A detailed analysis of the mechanism of transport of various ions through this new type of "track-etched" pores including molecular dynamics simulation has been performed in [107, 124].

\section{MATHEMATICAL MODELING OF POROUS STRUCTURES AND MEMBRANE SEPARATION PROCESSES}

The development of models of porous structures, which includes membranes as well, follows two lines, analytical and numerical. The analytical, integrated approach to the description of a fluid (electrolyte) flux 
through complex porous media using Brinkman, Stokes, Nernst-Planck, and Poisson equations is based on the application of thermodynamics of nonequilibrium processes and the cell method [125, 126], which allow taking into account the "fine" structure of the medium, namely, the size, hydrodynamic permeability, exchange capacity of grains or fibers forming it, and their packing pattern. In other words, two levels of pores, namely, the macropores formed by grains (e.g., of an ion exchanger) packed into array and the micro- and mesopores concentrated in the grains themselves, are taken into account. The main problem in the solution of such tasks consists in selecting correctly the conditions of flux coupling at the porous body/fluid interface, which problem is solved, in particular, by setting a jump in tangential stresses instead of the conventional continuity conditions or considering the slip on the impermeable boundary [127], so that the action of surface forces in the micro- and nanosized pores can be taken into account. Another problem is the consideration of the deviation of the shape of grains constituting the medium from a spherical or cylindrical form that is initially suggested in the model [127, 128], which is particularly important when describing mass transport through swollen polymer membranes when the grains are subjected to deformation. The third problem is associated with taking into account of external electromagnetic interference during the filtration of a conducting fluid [129, 130]. An interesting effect of a drop in the permeability of a fibrous porous medium in the case of penetration of a surfactant to the interface between the cylindrical fibers constituting the medium and the fluid being filtered has been described using the cell method [131]. Note that the overwhelming majority of works on the cell models of membranes deal with Newtonian fluids. Meanwhile, a class of non-Newtonian fluids, such as micropolar fluids, possesses wide possibilities for practical application and research. There are a number of flow properties known for quite a long time that do not find explanation in terms of the classical Newtonian fluid theory. They include abnormal changes in the rheological characteristics of fluids upon external electromagnetic interference, the formation of thin films and boundary layers with pronounced dependences of the properties on the characteristic scale near solid surfaces, the effects of a sharp increase in the flow rate in thin capillaries, and deviation of membrane filtration characteristics from those predicted by the classical theory of Newtonian fluid flirtation. Despite this, only several applications of the micropolar theory to cell models have been published so far [132-134], and there are no reports in which partially porous cells (an impermeable core covered with a porous shell) have been considered. Nevertheless, such cells make it possible to describe the loosening of the surface of membrane-constituting grains or fibers and adsorption of components of a solution on this surface during the filtration process. A detailed description of the cell method in the cylindrical geometry for a micropolar fluid is given in [132]. The classic model of a spherical cell with a liquid micropolar core surrounded by a nonpolar viscous shell and, on the opposite, a viscous core in a micropolar shell has been developed in [133]. In [134], the cell model for a viscous spheroid in a micropolar spheroidal shell has been studied. Analytical solutions for classical tasks in terms of a simple microfluid model and its main applications, as well as the formulated boundary value problems with specified boundary conditions for cylindrical and spherical cells with an impermeable core, a porous layer, and a micropolar fluid layer, are surveyed in [135].

The differential approach to modeling is based on the application of a system of known local transport equations to describe the transport of neutral components or ions and a solvent (water) through homogenized porous media (membranes) but, as opposed to the cell method, without regard for their fine structure. Pressure-driven membrane liquid separation processes, diffusion of gases through porous layers under pressure, etc. are generally considered using this approach. In connection with the fast development of the methods of surface and bulk modification of membranes by various dopants-preparation of hybrids and nanocomposites, the number of works devoted to the transport through multilayer membranes and membranes with thickness-gradient physicochemical characteristics grows. The effect of asymmetry of diffusion permeability discovered for such membranes more than 30 years ago, which occurs upon the change in their orientation relative to the direction of the gradient of the electrolyte concentration, was first theoretically explained for charged bilayer membranes in [136]. Asymmetry is observed for the rejection coefficient of bilayer (selective layer + substrate) and modified membranes upon pressuredriven membrane separation [137] and for the voltammetric curves of gradient-modified (e.g., by polyaniline) MF-4SK membranes [138]. The above-listed asymmetry effects have a potential perspective in the fabrication of membrane probes, sensors, and diodes, because of which their theoretical and experimental investigation appears to be fundamentally important. The main characteristic feature of the model [136] is the consideration of the specific interaction of ions from the electrolyte solution with the surface of membrane pores, which makes it possible to determine the exchange capacity and the electrolyte diffusion coefficient and describe the behavior of the integral coefficient of diffusion permeability with an increase in the $\mathrm{NaCl}$ and/or $\mathrm{HCl}$ concentration in the case of MF-4SK perfluorinated membranes modified with silica nanoparticles [139], alumina-based nanoporous membranes [140], and a strongly swollen (80-90\%) commercial regenerated cellulose membrane (cellulose content of $40 \mathrm{~g} / \mathrm{m}^{2}$ ) modified with a thiolated dendrimer using a dip coating method [141]. The reason for the found asymmetry effects is the nonlinearity of the problem- 
the variability of one or several physicochemical parameters, such as exchange capacity, diffusion coefficients, and interaction potential of molecules or ions with the pore surface, over the membrane thickness, which leads to the asymmetry of the concentration profile. For example, it was found [112] that the conical shape of the pore channel and, hence, the asymmetric distribution of the concentration of ions over the pore length are responsible for the asymmetry. The influence of the asymmetric gas concentration profile on the asymmetry of the transport coefficients of a bilayer membrane consisting of a fine-pore skin layer and a coarse-pore substrate has been shown in [142]. The asymmetry effect is determined by the difference in values between the parameters of the gas sorption isotherms in membrane layers [143] at the final gas pressure or by the ratio of the diffusion conductivities of the layers, mechanism of transport through the layers, and external pressure [144]. It was found based on a generalized model of a dusty gas that surface forces substantially affect the transport of a gas mixture through porous solids: the separation of the mixture components due to the difference in the interaction potentials of the constituent gas molecules with the pore surface is possible [145]. The electrolyte transport through a single pore of a nanofiltration membrane by the action of a pressure differential and a known zeta potential or charge density of its surface taking into account the interface effects at the inlet/outlet from the pore has been studied in [146]. Such a task provides the possibility for generalizing the model to a membrane with a specified pore size distribution density.

Fast development of computational tools makes it possible to perform calculations for porous structures with the pore space geometry set maximally close to the real geometry, which can be determined, e.g., using tomography. In particular, a model for a fluidsaturated pore-forming medium has been developed on the basis of a combination of the discrete element method and the grid method [147]. This model adequately considers the deformation, degradation, and multiscale internal structure of a porous solid framework, which is a significant step ahead in numerical modeling. Therefore, numerical and analytical methods for studying membrane transport naturally complete and enrich each other.

\section{MODERN ASPECTS OF THE THEORY AND SIMULATION OF ION AND WATER TRANSPORT IN MEMBRANE SYSTEMS}

The most important task of membrane science and engineering is the simultaneous improvment in the separation selectivity and productivity of a membrane process. In the field of gas-separation membranes, the Robeson trade-off is well known [148], according to which a growth in selectivity inevitably leads to a decrease in permeance and vice versa. The existence of such a trade-off in the field of ion-exchange membranes is evidenced by experimental studies [40, 149]. Many laboratories are engaged in searching for the theoretical upper bound of selectivity at a high productivity of the separation process.

According to Park et al. [2], the central problem in this field is the insufficiently good understanding of the structure-properties-performance relationships. A certain leap in this field was made by Kamcev and coworkers $[150,151]$, who revised the classical Donnan equilibrium relationships in systems with ionexchange membranes in terms of Manning's counterion condensation theory developed in the 1960s1970s for polyelectrolytes [152]. In particular, this theory makes it possible to calculate activity coefficients without adjustable parameters [150] and, therefore, to theoretically determine the Donnan equilibrium constant, which is usually found from the experiment. In [151], an approach has been developed that can serve as a basis for finding the theoretical values of selectivity and rate of transport through ion-exchange membranes [2].

Important questions of the theory of equilibrium of ion-exchange membranes are also the dependences of water concentration in a membrane and degree of its swelling on the concentration and $\mathrm{pH}$ of the external solution $[153,154]$. The shape of these dependences is determined by the nature of the fixed groups, in particular, the presence of secondary and tertiary amino groups [155].

It is believed $[2,39,156]$ that hybrid materials with a mixed organic-inorganic matrix are promising materials for achieving high selectivity and productivity. Generally, such materials consist of a dispersed phase of a nanosized inorganic material and a continuous polymer matrix. The mathematical description of ion transport in such a system presents considerable difficulties in view of the complexity of its geometry. The schematic layout of a fragment of a membrane with a mesopore containing a nanoparticle is presented in Fig. 3. In accordance with the physicochemical model of limited elasticity of membrane pore walls [39], it is assumed that nanoparticles can be immobilized in the meso- and macropores, but they do not penetrate into the system of micropores, in which counterions are "condensed" $[150,151]$. The mathematical description of the conductivity of membranes with nanoparticles is constructed on the basis of the known microheterogeneous model [157], which is successfully applied to the characterization of membranes [158, 159]. In [157], a membrane is considered as a two-phase system that contains the gel phase (system of micropores inside an ion-exchange matrix) and the liquid phase, an electroneutral solution that fills the internal part of the meso- and macropores. The input parameters of the model are the volume fraction of the gel phase (of the electroneutral solution), coefficients of diffusion in both phases, membrane capacity, and Donnan equilibrium constant. A common set 


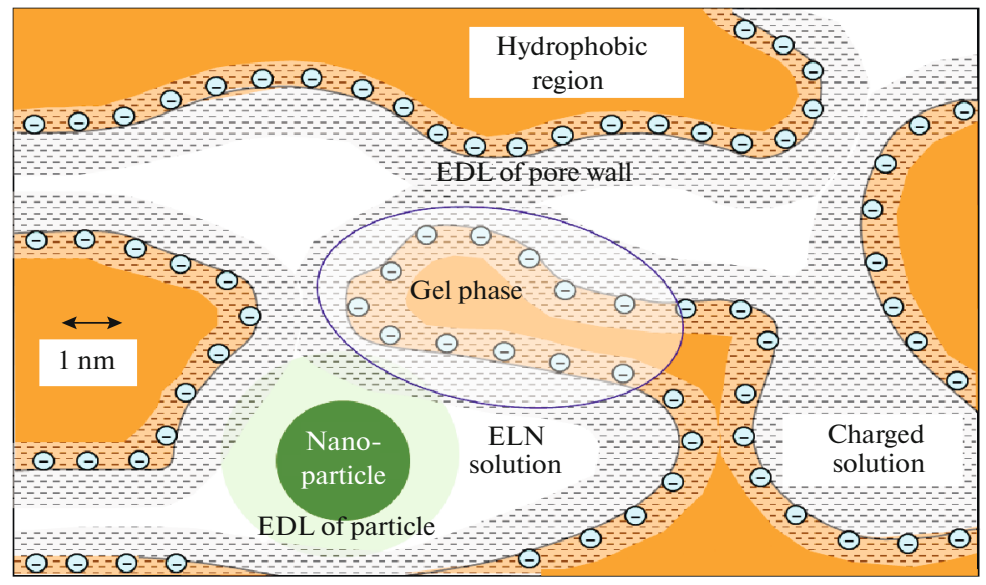

Fig. 3. Scheme of a membrane fragment. The gel phase includes a polymer matrix with fixed groups, the charge of which is compensated by the electrical double layer (EDL) in the internal solution near the pore wall. The solution in the central part of the pore is electroneutral (ELN). A nanoparticle with a charged surface surrounded by its own EDL is immobilized inside the mesopore.

of parameters makes it possible to adequately describe the concentration dependences of the following three membrane characteristics at once: specific electric conductivity, diffusion permeability, and transport numbers of ions $[157,160]$.

When considering the role of nanoparticles, two factors are taken into account, (1) the electrical double layer (EDL) around the particle (Fig. 3), which has higher conductivity than the electroneutral solution in the pore, and (2) the nonconducting core of the particle [161]. In the region of dilute solutions, the EDL has a significant thickness, which determines both the dominant role of the first factor and the experimental fact that the conductivity of a membrane with incorporated nanoparticles is higher than that of the initial membrane. In the region of more concentrated solutions, the EDL thickness is small and the presence of a nonconducting body in membrane pores becomes the main factor. However, this effect does not necessarily lead to a decrease in conductivity in comparison with the initial membrane because the presence of nanoparticles induces a growth in the osmotic internal pressure in the pores and an increase in the pore size [39]. It depends on the elasticity of the pore walls whether the effect of pore size growth would overlap the "nonconducting-body" effect or not.

Let us also note other theoretical approaches to the description of hybrid membranes. Filippov et al. [162, 163] have developed the so-called fine-pore model, suggesting a membrane to be a quasi-homogeneous medium, the thermodynamic and kinetic parameters of which depend on the presence of nanoparticles in the pores.

The model [161] can also be adapted [164] for the description of the influence of organic colloid particles formed in membrane pores by fouling (contamination/poisoning) of membranes during their opera- tion in solutions containing organic substances (in particular, dairy products, juices, and wines).

The rate-limiting steps of the transport depend on the membrane type and the nature of particles to be separated. In the case of gas separation, only the transport through the membrane plays a significant role, which substantially simplifies the theoretical estimations of the limits of selectivity and the rate of separation $[2,148]$. However, in the case of electrodialysis of dilute solutions, the rate-determining step is the transport of ions through the diffusion layer [165]. It is well known that with the growth in the current density $i$ (which is a measure of the rate of the electrodialysis process), the electrolyte concentration at the surface of an ion-exchange membrane decreases and becomes much lower than the concentration in the bulk of the solution at a certain value of $i=i_{\text {lim }}$, that is called the limiting current density. Here, the potential drop and, together with it, the power consumption start rapidly increasing. In this connection, the most important objective of increasing the performance of this process is the enhancement of ion transport through the diffusion layer. A significant number of studies [166-169] show that a substantial gain in current density above the value $i_{\text {lim }}$ (overlimiting transport) can be achieved if the membrane surface has a certain electric and geometric nonuniformity. In this case, the tangential transport of ions [170], which initiates the electroosmotic slip of the solution on the membrane surface (electroconvective transport), is essential [166-169]. Surfaces that spontaneously induce the stirring of the solution in an applied external electric field are promising for overlimiting transport. The fractions of conducting and nonconducting membrane surfaces are the subject of optimization. At a small fraction of conducting surface $\Theta$, the resistance of the solution near the membrane surface will be too high; when $\Theta$ 
approaches 1, the effect of tangential transport will become insignificant. The theoretical calculations in [168] and [171] showed that the dependence of the rate of mass transport at a fixed value of the potential drop on $\Theta$ is indeed nonmonotonic in character. According to [168], the maximum of the mass transport rate is achieved at $\Theta$ close to 0.5 ; the calculations of [171] give the optimum value of $\Theta \approx 0.8$. The difference is due to the fact that the absence of forced fluid flow in the channel is supposed in [168] while the calculation in [171] was performed with allowance for the flow of the solution, which corresponds to the common conditions of electrodialysis.

\section{DEVELOPMENTS OF MEMBRANE MATERIALS FOR PERVAPORATION PROCESSES}

Pervaporation (evaporation through a membrane) is a membrane-based process in which the feed and retentate streams are both liquid phases while permeant emerges at the downstream face of the membrane as a vapor. Currently, pervaporative drying of organic solvents using a vacuum process scheme (reduced pressure from the permeate side) is implemented on an industrial scale. At the same time, thermopervaporation possesses higher potential for its commercial application in the recovery of organic components from aqueous media [172]. The separation and condensation of the permeate in thermopervaporation occurs directly in the membrane module under atmospheric pressure.

To develop this approach, a new concept of thermopervaporation that makes it possible to intensify the separation process and implement it on an industrial scale was proposed and fulfilled [173]. The main difference of the new concept of thermopervaporation consists in the design of the membrane module, in which the condensation surface is not a dense plate but a porous partition. In this case, the condensed permeate is used as the coolant. The proposed thermopervaporation concept made it possible to create a new hybrid method for the recovery and concentration of biobutanol, acetone, and ethanol from fermentation mixtures, in which thermopervaporative separation is combined with the phase separation of sparingly compatible aqueous-organic mixtures [174].

Currently, polydimethylsiloxane (PDMS) membranes are the most widely used materials in the recovery of alcohols and other organic components from aqueous media. Almost all the existing commercial hydrophobic membranes are produced on the basis of crosslinked PDMS by applying a thin selective layer (to $5 \mu \mathrm{m}$ ) onto porous polymer substrates. Such flat sheet membranes demonstrate high and stable permeate fluxes but, however, insufficiently high values of the separation factor, among other reasons, because of the polymer swelling in the feed media $[175,176]$. The use of tubular and hollow-fiber porous ceramic mem- branes as substrates made it possible to substantially increase the separation factor and productivity of composite membranes with a thin selective layer made of crosslinked PDMS [177, 178]. The partial penetration of the selective PDMS layer into the rigid ceramic matrix of the substrate limits the degree of polymer swelling; this is the most likely reason for the increased values of the separation factor of composite membranes made of PDMS on a ceramic substrate.

A promising technique for imparting increased selectivity for organic components to polysiloxanes is the introduction of hydrophobic hydrocarbon moieties into their structure $[179,180]$. Thus, to recover alcohols from aqueous effluents by pervaporation, a new membrane made of polymethylsiloxane bearing 1-heptene as substituent in side chains has been created [180]. It has been shown that polyheptylmethylsiloxane is the most promising membrane material for the pervaporative separation of water-butanol mixtures. This polymer demonstrates the record-high water/butanol separation factor of 97. Also, polyalkylenesiloxanes were studied for the first time as pervaporation membrane materials for the recovery of butanol from aqueous media [181]. It has been shown that the butanol/water permselectivity of these membranes is almost twice as high as that of PDMS at comparable values of the butanol permeability coefficient.

In recent years, significant efforts of researchers have also focused on the development of hybrid materials and investigation of the pervaporation properties of so-called mixed-matrix membranes. To enhance the pervaporation characteristics of hydrophilic membranes based on polyvinyl alcohol (PVA), modifying additives made of polyhydroxy fullerenes are successfully used [182-184]. In comparison with fullerene, fullerenols possess high solubility in water and are significantly better incorporated into the polymer matrix. The modification by fullerenols makes it possible to decrease the sorption of water and increase the mechanical properties of PVA membranes. As a result, in the case of pervaporative dehydration of water-ethanol mixtures, PVA membranes with a $\mathrm{C}_{60}(\mathrm{OH})_{22-24}$ concentration of $5 \mathrm{wt} \%$ demonstrate increased values of the permeate flux and selectivity in comparison with the unmodified membranes [182].

Today, a keen interest of researchers is also attracted by graphene as a new membrane material [185]. Thus, its oxidized form (graphene oxide) is used for the preparation of highly efficient pervaporation membranes with superthin selective layers. It was shown that a membrane made of graphene oxide (GO) with a thickness of $93 \mathrm{~nm}$ can provide a permeate flux of $2.2 \mathrm{~kg} \mathrm{~m}^{-2} \mathrm{~h}^{-1}$ and a separation factor of 308 in the case of pervaporative dehydration of a $80 \mathrm{wt} \%$ ethanol aqueous solution $\left(70^{\circ} \mathrm{C}\right)$ [186]. In [187], in the case of dehydration of a $70 \mathrm{wt} \%$ aqueous solution of isopropanol $\left(70^{\circ} \mathrm{C}\right)$, a composite membrane made of GO on a porous polyacrylonitrile substrate demonstrated a 
flux of $4.4 \mathrm{~kg} \mathrm{~m}^{-2} \mathrm{~h}^{-1}$ and a separation factor of 1160 . These results confirm the high potential of graphene oxide-based pervaporation membranes for the tasks of drying of organic solvents.

The most complex problem is the creation of membranes for the separation of organic mixtures. Chemically and thermally stable polymers, such as polyimides [188] or polyether ether ketone, are used for this purpose [189]. To increase the separation efficiency, inorganic nanoparticles, such as GO [190, 191], carbon nanotubes [192], and MOFs, are added to the polymer matrix [193].

One of the most important problems in pervaporation is concentration polarization, which often leads to a decrease in the efficiency of the pervaporative separation process. This effect is associated with the resistance to the transport of the selectively penetrating component in the boundary layer of the fluid near the membrane surface. For the fast estimation of the contribution from this phenomenon to the pervaporation process, a new and simple approach to the modeling of the effect of concentration polarization on the pervaporation process using highly permeable hydrophobic membranes was proposed [194]. The main advantage of the model proposed is that all the required values are calculated exclusively on the basis of the experimental data obtained at different velocities of the feed mixture.

\section{INCREASING THE PERFORMANCE OF PRESSURE-DRIVEN MEMBRANE PROCESSES}

The traditional field of application of pressuredriven membrane processes (micro-, ultra-, and nanofiltration and reverse osmosis) is wastewater treatment, water conditioning, and production of drinking water [195-198]. Today in the world, over 100 million $\mathrm{m}^{3}$ of fresh water a day is produced by desalination of sea water with membranes, where the share of reverse osmosis is about 60\% [198]. The progress in the development of membranes, membrane modules, and engineering of the desalination process made it possible to decrease the cost of $1 \mathrm{~m}^{3}$ of produced fresh water from $\$ 1.25$ to $\$ 0.44$ over the last 20 years, with substantial attention being paid to recycling the concentrates [198, 199]. Note that the concentration and recovery of dissolved metals often makes it possible to counterbalnce the expenditures for the production of drinking water [200]. Pressuredriven membrane processes are used for the purification of waste and process waters in food industry (clarification and preparation of juice concentrates, nonthermal sterilization, and processing of milk whey), pharmaceutical industry, etc. [201-204].

Considerable progress has also been achieved in the field of separation of organic media. The separation of the reaction mixture and purification of the target component are one of the most energy-consuming stages of many petrochemical processes and can reach up to $70 \%$ of all the operational costs. Successful application of nanofiltration made it possible to increase the productivity of a motor oil unit by $25 \%$ and to decrease the concentration of paraffins by 3-5 wt \% [205]. Pressuredriven membrane processes are applied for the recovery of homogeneous catalysts from the reaction mixture for the subsequent return to the chemical reactor, nonthermal replacement of solvents in multistage organic syntheses, and recycle of extraction solvents in the production of vegetable oils and purification of fuels [206-208]. To increase the membrane resistance, it has been proposed to perform additional crosslinking and thermal treatment [209-211].

The development of new membranes for the separation and purification of aqueous and organic media remains an important task. Low-permeability glassy polymers (polysulfones, aromatic polyamides, polyimides,etc.) have been utilized for fabrication of filtration asymmetric membranes with a nanoporous selective layer [207]. Glassy polymers with a high fractional free volume are widely used for the organic solvent nanofiltration [212]. Despite the high mechanical stability and absence of swelling, inorganic nanofiltration membranes are used less often than widely available and relatively cheap polymer membranes [213, 214].

\section{CONCLUSIONS}

The world of membranes is broad and extremely diverse. However, there is a thing that unifies absolutely different types of membranes with different structures and compositions-all of them are designed for application in different technologies. In most of their applications, the main requirements to membrane materials are selectivity, productivity, and stability. Moreover, there are other important parameters including strength, cost, etc. In the case of large-scale applications, e.g., such as water treatment, the cost of membranes is critical and, thus, baro- and electromembrane technologies using relatively cheap membranes are in high demand for this purpose, while expensive highly selective membranes of the Nafion type are not used in it. At the same time, when designing fuel cells, high stability and selectivity play the pivotal role, which determines the completely different range of materials to be used. Nevertheless, this does not lead to a decrease in the torrent of works dealing with the fabrication of new relatively cheap membranes characterized by high selectivity and productivity. Among other things, interest in the modification of the bulk of the membranes or their surface grows as well.

In addition, the ratio of demands for membrane processes permanently changes. Currently, membrane technologies are the most sought for in the water treatment processes, medicine, and chemical industry. However, a heavy growth in the application of membrane technologies in electric power industry and bio- 
chemistry is observed. At the same time, some shift of the interest is also observed in the conventional fields. Thus, in water treatment systems, significant attention started being paid not only to the production of pure water from natural and waste waters, but also to the recovery of some valuable products from the latter, which will soon have a significantly greater value in connection with the gradual exhaustion of natural resources. In this connection, there is increasing interest, e.g., in membranes that selectively transport not only ions bearing a charge of a certain sign, but also singly or doubly charged ions and even ions having a certain composition. Thus, the development of membrane science will continue and new prospects for using membrane technologies will emerge.

\section{REFERENCES}

1. M. Galizia, W. S. Chi, Z. P. Smith, et al., Macromolecules 50, 7809 (2017).

2. H. B. Park, J. Kamcev, L. M. Robeson, et al., Science 356, 6343 (2017).

3. K. F. L. Hagesteijn, S. Jiang, and B. P. Ladewig, J. Mater. Sci. 53, 11131 (2018).

4. T. Luo, S. Abdu, and M. Wessling, J. Membr. Sci. 555, 429 (2018).

5. Yu. Yampolskii, Macromolecules 45, 3298 (2012).

6. D. F. Sanders, Z. P. Smith, R. Guo, et al., Polymer 54, 4729 (2013).

7. P. M. Budd, E. S. Elabas, B. S. Ghanem, et al., Adv. Mater. 16, 456 (2004).

8. P. M. Budd, N. B. McKeown, B. S. Ghanem, et al., J. Membr. Sci. 325, 851 (2008).

9. A. F. Bushell, M. P. Attfield, C. R. Mason, et al., J. Membr. Sci. 427, 48 (2013).

10. E. Tocci, L. De Lorenzo, P. Bernardo, et al., Macromolecules 47, 7900 (2014).

11. M. Carta, R. Malpass-Evans, M. Croad, et al., Science 339, 303 (2013).

12. L. Starannikova, N. Belov, V. Shantarovich, et al., J. Membr. Sci. 548, 593 (2018).

13. C. Zhang, L. Fu, Z. Tian, et al., J. Membr. Sci. 556, 277 (2018).

14. X. Ma, M. A. Abdulhamid, and I. Pinnau, Macromolecules 50, 5850 (2017).

15. C. H. Lau, P. T. Nguyen, M. R. Hill, et al., Angew. Chem., Int. Ed. Engl. 53, 5322 (2014).

16. T. C. Merkel, I. Pinnau, R. Prabhakar, and B. D. Freeman, Materials Science of Membranes for Gas and Vapor Separation, Ed. by Yu. Yampolskii, I. Pinnau, and B. D. Freeman (Wiley. Chichester, 2006), p. 251.

17. N. Belov, R. Nikiforov, E. Polunin, et al., J. Membr. Sci. 565, 112 (2018).

18. R. Nikiforov, N. Belov, A. Zharov, et al., J. Membr. Sci. 540, 129 (2017).

19. M. Yavari, M. Fang, H. Nguyen, et al., Macromolecules 51, 5889 (2018).

20. M. Mukaddam, E. Litwiller, and I. Pinnau, Macromolecules 49, 280 (2016).
21. T. Sakaguchi, Y. Hu, and T. Masuda, Membrane Materials for Gas and Vapor Separation: Synthesis and Application of Silicon-Containing Polymers, Ed. by Yu. Yampolskii and E. Finkelshtein (Wiley, Chichester, 2017), p.107.

22. E. Finkelshtein, M. Gringolts, M. Bermeshev, et al., Membrane Materials for Gas and Vapor Separation: Synthesis and Application of Silicon-Containing Polymers, Ed. by Yu. Yampolskii and E. Finkelshtein (Wiley, Chichester, 2017), p. 143.

23. M. Gringolts, M. Bermeshev, Yu. Yampolskii, et al., Macromolecules 43, 7165 (2010).

24. P. P. Chapala, M. V. Bermeshev, L. E. Starannikova, et al., Macromolecules 48, 8055 (2015).

25. D. A. Alentiev, E. S. Egorova, M. V. Bermeshev, et al., J. Mater. Chem. A 6, 19393 (2018).

26. N. Belov, R. Nikiforov, L. Starannikova, et al., Eur. Polym. J. 93, 602 (2017).

27. J. T. Vaughn, D. J. Harrigan, B. J. Sundellet al., J. Membr. Sci. 522, 68 (2017).

28. G. A. Khakpay and P. Scovazzo, J. Membr. Sci. 545, 204 (2018).

29. D. I. Petukhov, M. V. Berekchiian, E. S. Pyatkov, et al., J. Phys. Chem. C 120, 10982 (2016).

30. E. S. Pyatkov, V. N. Surtaev, D. I. Petukhov, et al., Oil Ind. J. 5, 82 (2016).

31. A. B. Yaroslavtsev and Yu. P. Yampolskii, Mendeleev Commun. 24, 319 (2014).

32. X. Ma, P. Kumar, N. Meittal, A. Khlyustova, et al., Science 361, 1008 (2018).

33. H. Strathmann, A. Grabowski, and G. Eigenberger, Ind. Eng. Chem. Res. 52, 10364 (2013).

34. Y. Tanaka, Ion Exchange Membranes: Fundamentals and Applications, 2nd Ed. (Elsevier, Amsterdam, 2015).

35. E. Yu. Safronova and A. B. Yaroslavtsev, Pet. Chem. 56, 281 (2016).

36. R. Ashu, S. Pawlowski, J. Veerman, et al., Appl. Energy 225, 290 (2018).

37. K. A. Mauritz and R. B. Moore, Chem. Rev. 104, 4535 (2004).

38. V. V. Nikonenko, A. B. Yaroslavtsev, and G. Pourcelly, Ionic Interactions in Natural and Synthetic Macromolecules, Ed. by A. Ciferri and A. Perico (Wiley, Hoboken, 2012).

39. A. B. Yaroslavtsev, Nanotechnol. Russ. 7, 437 (2012).

40. D. V. Golubenko, G. Pourcelly, and A. B. Yaroslavtsev, Sep. Purif. Technol. 207, 329 (2018).

41. N. Kononenko, V. Nikonenko, D. Grande, et al., Adv. Colloid Interface Sci. 246, 196 (2017).

42. E. Yu. Safronova, D. V. Golubenko, N. V. Shevlyakova, et al., J. Membr. Sci. 515, 196 (2016).

43. D. V. Golubenko and A. B. Yaroslavtsev, Mendeleev Commun. 27, 572 (2017).

44. D. A. Kritskaya, E. F. Abdrashitov, V. Ch. Bokun, and A. N. Ponomarev, Pet. Chem. 58, 309 (2018).

45. D. V. Golubenko, E. Y. Safronova, A. B. Ilyin, et al., Mater. Chem. Phys. 197, 192 (2017).

46. L. Ge, A. N. Mondal, X. Liu, et al., J. Membr. Sci. 536, 11 (2017). 
47. L. Ge, B. Wu, D. Yu, et al., Chin. J. Chem. Eng. 25, 1606 (2017).

48. M. Reig, H. Farrokhzad, B. van der Bruggen, et al., Desalination 375, 1 (2015).

49. X.-Y. Nie, S.-Y. Sun, X. Song, and J.-G. Yu, J. Membr. Sci. 530, 185 (2017).

50. J. Ran, L. Wu, Y. He, et al., J. Membr. Sci. 522, 267 (2017).

51. T. Sata, J. Membr. Sci. 167, 1 (2000).

52. D. V. Golubenko, Yu. A. Karavanova, S. S. Melnikov, et al., J. Membr. Sci. 563, 777 (2018).

53. L. Krasemann and B. Tieke, Langmuir 16, 287 (2000).

54. Y. Zhao, K. Tang, H. Liu, et al., J. Membr. Sci. 520, 262 (2016).

55. Y. Zhao, J. Zhu, J. Ding, et al., J. Membr. Sci. 548, 81 (2018).

56. S. Abdu, M.-C. Marti-Calatyud, J. E. Wong, et al., ACS Appl. Mater. Interfaces 6, 1843 (2014).

57. N. White, M. Misovich, A. Yaroshchuk, and M. L. Bruening, ACS Appl. Mater. Interfaces 7, 6620 (2015).

58. T. Xu, J. Membr. Sci. 263, 1 (2005).

59. S. Bose, T. Kuila, T. X. Hien Nguyen, et al., Progr. Polym. Sci. 36, 813 (2011).

60. H. Vinh-Thang and S. Kaliaguine, Chem. Rev. 113, 4980 (2013).

61. Y. Gu, R. M. Dorin, and U. Wiesner, Nano Lett. 13, $5323(2013)$.

62. A. B. Yaroslavtsev, Yu. A. Karavanova, and E. Yu. Safronova, Pet. Chem. 51, 473 (2011).

63. A. K. Osipov, A. O. Volkov, E. Yu. Safronova, and A. B. Yaroslavtsev, Russ. J. Inorg. Chem. 62, 723 (2017).

64. I. A. Prikhno, K. A. Ivanova, G. M. Don, and A. B. Yaroslavtsev, Mendeleev Commun. 28, 657 (2018).

65. E. Gerasimova, E. Safronova, A. Ukshe, et al., Chem. Eng. J. 305, 121 (2016).

66. I. A. Stenina, E. Yu. Voropaeva, A. A. Ilyina, and A. B. Yaroslavtsev, Polym. Adv. Technol. 20, 566 (2009).

67. Z. Zakaria, S. K. Kamarudin, and S. N. Timmiati, Appl. Energy 163, 334 (2016).

68. S. S. Munjewar, S. B. Thombre, and R. K. Mallick, Renew. Sust. Energy Rev. 67, 1087 (2017).

69. J.-H. Kim, S.-K. Kim, K. Nam, and D.-W. Kim, J. Membr. Sci. 415-416, 696 (2012).

70. A. H. Haghighi, M. Tohidian, A. Ghaderian, and S. E. Shakeri, J. Macromol. Sci., Part B: Phys. 56, 383 (2017).

71. E. Bakangura, L. Wu, L. Ge, et al., Progr. Polym. Sci. 57, 103 (2016).

72. D. Ju, K. M. Jae, J. Sang, and Y. Nam, J. Ind. Eng. Chem. 21, 36 (2015).

73. P. Baker, M. Lavorgna, Q. Wu, et al., J. Power Sources 403, 118 (2018).

74. A. G. Mikheev, E. Yu. Safronova, G. Yu. Yurkov, and A. B. Yaroslavtsev, Mendeleev Commun. 23, 66 (2013).

75. J. Ahn, W.-J. Chung, I. Pinnau, et al., J. Membr. Sci. 346, 280 (2010).

76. M. M. Khan, V. Filiz, G. Bengtson, et al., J. Membr. Sci. 436, 109 (2013).
77. E. Karatay, H. Kalipcilar, and L. Yilmaz, J. Membr. Sci. 364, 75 (2010).

78. P. Gorgojo, D. Sieffert, C. Staudt, et al., J. Membr. Sci. 411-412, 146 (2012).

79. H. Dong, K.-J. Xiao, X.-L. Li, et al., Desalin. Water Treat. 51, 3677 (2013).

80. E. Safronova, A. Parshina, T. Kolganova, et al., J. Electroanal. Chem. 816, 21 (2018).

81. I. A. Pechenkina and K. N. Mikhelson, Russ. J. Electrochem. 51, 93 (2015).

82. K. N. Mikhelson and M. A. Peshkova, Russ. Chem. Rev. 84, 555 (2015).

83. N. M. Makarova, E. G. Kulapina, A. A. Kolotvin, and E. S. Pogorelova, J. Anal. Chem. 72, 87 (2017).

84. I. Timofeeva, K. Medinskaia, L. Nikolaeva, et al., Talanta 150, 655 (2016).

85. T. Yin and W. Qin, TrAC Trends Anal. Chem. 51, 79 (2013).

86. M. Sorvin, S. Belyakova, I. Stoikov, et al., Front. Chem. 6, 134 (2018).

87. L. Lvova, I. Yaroshenko, D. Kirsanov, et al., Sensors 18, 2584 (2018).

88. L. van de Velde, E. d'Angremont, and W. Olthuis, Talanta 160, 56 (2016).

89. S. Wang, Y. Kang, and L. Wang, Sens. Actuators, B 182, 467 (2013).

90. M. M. Barsan, M. E. Ghica, and C. M. A. Brett, Anal. Chim. Acta 881, 1 (2015).

91. R. Athavale, I. Kokorite, C. Dinkel, et al., Anal. Chem. 87, 11990 (2015).

92. M. A. Deshmukh, M. D. Shirsat, A. Ramanaviciene, and A. Ramanavicius, Crit. Rev. Anal. Chem. 48, 293 (2018).

93. N. Yusoff, P. Rameshkumar, and N. M. Huang, Microchim. Acta 185, 246 (2018).

94. T. Yin, D. Pan, and W. Qin, J. Solid State Electrochem. 16, 499 (2012).

95. M. Parrilla, R. Canovas, and F. J. Andrade, Electroanalysis 29, 223 (2017).

96. A. V. Parshina, T. S. Denisova, E. Yu. Safronova, et al., J. Anal. Chem. 72, 1243 (2017).

97. A. V. Parshina, T. S. Denisova, and O. V. Bobreshova, Pet. Chem. 56, 995 (2016).

98. E. Yu. Safronova, A. V. Parshina, E. A. Ryzhkova, et al., Russ. J. Inorg. Chem. 61, 1512 (2016).

99. E. Safronova, D. Safronov, A. Lysova, et al., Sens. Actuators, B 240, 1016 (2017).

100. P. Yu. Apel and S. N. Dmitriev, Membranes and Membrane Technologies, Ed. by A. B. Yaroslavtsev (Nauchnyi Mir, Moscow, 2013), p. 126 [in Russian].

101. H. Hanot and E. Ferain, Nucl. Instrum. Methods Phys. Res., Sect. B 267, 1019 (2009).

102. Z. S. Siwy, Adv. Funct. Mater, 16, 735 (2006).

103. J. Cervera, P. Ramirez, S. Mafe, and P. Stroeve, Electrochim. Acta 56, 4504 (2011).

104. A. Kocer, L. Tauk, and P. Dejardin, Biosens. Bioelectron. 38, 1 (2012).

105. M. Barsbay and O. Guven, Radiat. Phys. Chem. 105, 26 (2014).

Vol. $1 \quad$ No. $2 \quad 2019$ 
106. M. Lepoitevin, T. Ma, M. Bechelany, et al., Adv. Colloid Interface Sci. 250, 195 (2017).

107. F. Liu, M. Wang, X. Wang, et al., Nanotechnology 30, 052001 (2019). doi org/10.1088/1361-6528/aaed6d

108. R. Spohr, Radiat. Meas. 40, 191 (2005).

109. V. V. Bagrov, A. V. Desyatov, N. N. Kazantseva, et al., Water: Effects and Technologies, Ed. by A. V. Desyatov (NITs Inzhener, Oniko-M, Moscow, 2010), p. 61 [in Russian].

110. P. Yu. Apel, I. V. Blonskaya, N. V. Levkovich, and O. L. Orelovich, Pet. Chem. 51, 555 (2011).

111. P. Y. Apel, V. V. Bashevoy, I. V. Blonskaya, et al., Phys. Chem. Chem. Phys. 18, 25421 (2016).

112. P. Yu. Apel, I. V. Blonskaya, N. E. Lizunov, et al., Russ. J. Electrochem. 53, 58 (2017).

113. Y. Choi, L. A. Baker, H. Hillebrenner, and C. R. Martin, Phys. Chem. Chem. Phys. 8, 4976 (2006).

114. P. Ramirez, P. Y. Apel, J. Cervera, and S. Mafe, Nanotechnology 19, 315707 (2008).

115. L. T. Sexton, L. P. Horne, S. A. Sherrill, et al., J. Am. Chem. Soc. 129, 13144 (2007).

116. I. Vlassiouk, T. R. Kozel, and Z. S. Siwy, J. Am. Chem. Soc. 131, 8211 (2009).

117. J. Cervera, P. Ramirez, V. Gomez, et al., Appl. Phys. Lett. 108, 253701 (2016).

118. S. F. Buchsbaum, G. Nguyen, S. Howorka, and Z. S. Siwy, J. Am. Chem. Soc. 136, 9902 (2014).

119. K. Xiao, L. Wen, and L. Jiang, Small 12, 2810 (2016).

120. S. Balme, F. Picaud, M. Manghi, et al., Sci. Rep. 5, 10135 (2015).

121. K. R. Wigginton and P. J. Vikesland, Analyst 135, 1320 (2010).

122. O. V. Kristavchuk, I. V. Nikiforov, V. I. Kukushkin, et al., Colloid J. 79, 637 (2017).

123. M. E. Toimil-Molares, Beilstein J. Nanotechnol. 3, 860 (2012)

124. P. Wang, M. Wang, F. Liu, et al., Nat. Commun. 9, 569 (2018).

125. S. Deo, A. Filippov, A. Tiwari, et al., Adv. Colloid Interface Sci. 164, 21 (2011).

126. A. N. Filippov, Colloid J. 80, 716 (2018).

127. P. K. Yadav, A. Tiwari, and P. Singh, Acta Mech. 229, 1869 (2018).

128. S. Deo and B. R. Gupta, Acta Mech. 203, 241 (2009).

129. D. V. Jayalakshmamma, P. A. Dinesh, and M. Sankar, Mapana J. Sci. 10, 11 (2011).

130. P. K. Yadav, S. Deo, S. P. Singh, and A. Filippov, Colloid J. 79, 160 (2017).

131. S. Raturi, S. Datta, and B. V. Kumar Ratish, Eur. J. Mech. 71, 151 (2018).

132. H. H. Sherief, M. S. Faltas, E. A. Ashmawy, and A. M. Abdel-Hameid, Eur. Phys. J. Plus 12, 217 (2014).

133. E. I. Saad, Meccanica 47, 2055 (2012).

134. M. K. Prasad and M. Kaur, Eur. J. Mech. 65, 312 (2017).

135. D. Yu. Khanukaeva and A. N. Filippov, Colloid J. 80, 14 (2018).

136. A. N. Filippov, V. M. Starov, N. A. Kononenko, and N. P. Berezina, Adv. Colloid Interface Sci. 139, 29 (2008).
137. A. N. Filippov, N. A. Kononenko, S. I. Vasin, et al., Colloid J. 72, 846 (2010).

138. A. N. Filippov, Russ. J. Electrochem. 53, 257 (2017).

139. A. N. Filippov, E. Yu. Safronova, and A. B. Yaroslavtsev, J. Membr. Sci. 471, 110 (2014).

140. M. I. Vazquez, V. Romero, V. Vega, et al., Nanomaterials 5, 2192 (2015).

141. M. I. Vazquez, M. Algarra, and J. Benavente, Carbohydr. Polym. 131, 273 (2015).

142. V. M. Zhdanov, V. I. Roldugin, and E. E. Sherysheva, Colloid J. 72, 633 (2010).

143. V. V. Ugrozov, Colloid J. 80, 207 (2018).

144. V. V. Ugrozov, Colloid J. 80, 326 (2018).

145. V. I. Roldugin, V. M. Zhdanov, and A. V. Shabatin, Colloid J. 78, 652 (2016).

146. I. I. Ryzhkov and A. V. Minakov, J. Membr. Sci. 520, 515 (2016).

147. S. G. Psakhie, A. V. Dimaki, E. V. Shilko, and S. V. Astafurov, Int. J. Numer. Methods Eng. 106, 623 (2016).

148. L. M. Robeson, Q. Liu, B. D. Freeman, and D. R. Paul, J. Membr. Sci. 476, 421 (2015).

149. M. Geise, M. A. Hickner, and B. E. Logan, ACS Appl. Mater. Interfaces 5, 10294 (2013).

150. J. Kamcev, D. R. Paul, and B. D. Freeman, Macromolecules 48, 8011 (2015).

151. J. Kamcev, D. R. Paul, G. S. Manning, and B. D. Freeman, ACS Appl. Mater. Interfaces 9, 4044 (2017).

152. G. S. Manning, J. Chem. Phys. 51, 924 (1969).

153. A. D. Drozdov and C. J. de Claville, Int. J. SolidsStruct. 110, 192 (2017).

154. A. E. Kozmai, V. V. Nikonenko, S. Zyryanova, et al., J. Membr. Sci. 567, 127 (2018).

155. S. V. Zyryanova, N. D. Pismenskaya, and V. V. Nikonenko, Pet. Chem. 58, 965 (2018).

156. T.-S. Chung, L. Y. Jiang, Y. Li, and S. Kulprathipanja, Prog. Polym. Sci. 32, 483 (2007).

157. V. I. Zabolotsky and V. V. Nikonenko, J. Membr. Sci. 79, 181 (1993).

158. N. P. Berezina, N. A. Kononenko, O. A. Dyomina, and N. P. Gnusin, Adv. Colloid Interface Sci. 139, 3 (2008).

159. Y. Sedkaoui, A. Szymczyk, H. Lounici, and O. Arous, J. Membr. Sci. 507, 34 (2016).

160. N. D. Pismenskaya, E. E. Nevakshenova, and V. V. Nikonenko, Pet. Chem. 58, 465 (2018).

161. M. Porozhnyy, P. Huguet, M. Cretin, et al., Int. J. Hydrogen Energy 41, 15605 (2016).

162. A. Filippov, D. Afonin, N. Kononenko, et al., Colloids Surf., A 521, 251 (2017).

163. A. N. Filippov and S. A. Shkirskaya, Pet. Chem. 58, 774 (2018).

164. M. V. Porozhnyy, V. V. Sarapulova, N. D. Pismenskaya, et al., Pet. Chem. 57, 511 (2017).

165. P. E. Dlugolecki, P. Ogonowski, S. J. Metz, et al., J. Membr. Sci. 349, 369 (2010).

166. I. Rubinstein and B. Zaltzman, Phys. Rev. E 62, 2238 (2000). 
167. N. A. Mishchuk, Curr. Opin. Colloid Interface Sci. 18, 137 (2013).

168. S. M. Davidson, M. Wessling, and A. Mani, Sci. Rep. 6, 22505 (2016).

169. V. V. Nikonenko, V. I. Vasil'eva, E. M. Akberova, et al., Adv. Colloid Interface Sci. 235, 233 (2016).

170. S. A. Mareev, V. S. Nichka, D. Y. Butylskii, et al., J. Phys. Chem. C 120, 13113 (2016).

171. V. I. Zabolotsky, L. Novak, A. V. Kovalenko, et al., Pet. Chem. 57, 779 (2017).

172. H. J. Huang, S. Ramaswamy, and Y. Liu, Sep. Purif. Technol. 132, 513 (2014).

173. A. V. Volkov, E. G. Novitsky, I. L. Borisov, et al., Sep. Purif. Technol. 171, 191 (2016).

174. I. L. Borisov, G. S. Golubev, V. P. Vasilevsky, et al., J. Membr. Sci. 523, 291 (2017).

175. G. S. Golubev, I. L. Borisov, and V. V. Volkov, Pet. Chem. 58, 975 (2018).

176. G. S. Golubev, I. L. Borisov, and V. V. Volkov, Russ. J. Appl. Chem. 91, 1375 (2018).

177. Z. Dong, G. Liu, S. Liu, et al., J. Membr. Sci. 450, 38 (2014).

178. F. Xiangli, Y. Chen, W. Jin, and N. Xu, Ind. Eng. Chem. Res. 46, 2224 (2007).

179. A. Rom and A. Friedl, Sep. Purif. Technol. 170, 40 (2016).

180. E. A. Grushevenko, I. A. Podtynnikov, G. S. Golubev, et al., Pet. Chem. 58, 941 (2018).

181. I. L. Borisov, N. V. Ushakov, V. V. Volkov, and E. Sh. Finkel'shtein, Pet. Chem. 56, 800 (2016).

182. A. V. Penkova, S. F. Acquah, M. E. Dmitrenko, et al., Carbon 76, 446 (2014).

183. A. V. Penkova, S. F. Acquah, M. P. Sokolova, et al., J. Membr. Sci. 491, 22 (2015).

184. A. V. Penkova, M. E. Dmitrenko, S. S. Ermakov, et al., Environ. Sci. Pollut. Res. 25, 20354 (2018).

185. P. Z. Sun, K. L. Wang, and H. W. Zhu, Adv. Mater. 28, 2287 (2016).

186. T. M. Yeh, Z. Wang, D. Mahajan, et5 al., J. Mater. Chem., A 1, 12998 (2013).

187. W. S. Hung, Q. F. An, M. de Guzman, et al., Carbon 68, 670 (2014).

188. G. Kung, L. Y. Jiang, Y. Wang, and T. S. Chung, J. Membr. Sci. 360, 303 (2010).

189. S. Zereshki, A. Figoli, S. S. Madaeni, et al., J. Membr. Sci. 371, 1 (2011).

190. N. Wang, S. Ji, J. Li, et al., J. Membr. Sci. 455, 113 (2014).

191. D. Yang, S. Yang, Z. Jiang, et al., J. Membr. Sci. 487, $152(2015)$.
192. J. N. Shen, Y. X. Chu, H. M. Ruan, et al., J. Membr. Sci. 462, 160 (2014).

193. Z. Jia and G. Wu, Microporous Mesoporous Mater. 235, 151 (2016).

194. I. L. Borisov, A. Kujawska, K. Knozowska, et al., J. Membr. Sci. 564, 1 (2018).

195. B. Van der Bruggen, C. Vandecasteele, T. van Gestel, et al., Environ. Prog. 22, 46 (2003).

196. B. E. Ryabchikov, A. A. Panteleev, and M. G. Gladush, Pet. Chem. 52, 465 (2012).

197. V. G. Dzyubenko, P. A. Vdovin, A. R. Sidorov, and I. I. Shishova, Pet. Chem. 58, 733 (2018).

198. Green Chemistry and Sustainable Technology: Sustainable Membrane Technology for Water and Wastewater Treatment, Ed. by A. Figoli and A. Criscuoli (Springer, Singapore, 2017).

199. A. G. Pervov, A. P. Andrianov, and E. B. Yurchevskiy, Pet. Chem. 55, 871 (2015).

200. F. Macedonio and E. Drioli, Membrane-Based Desalination: An Integrated Approach, Ed. by E. Drioli, A. Criscuoli, and F. Macedonio (IWA, London. 2011), ch. 8.

201. V. A. Timkin and V. A. Lazarev, Pet. Chem. 55, 301 (2015).

202. V. P. Kasperchik, A. L. Yaskevich, and A. V. Bil'dyukevich, Membr. Membr. Tekhnol. 2, 133 (2012).

203. A. G. Pervov and N. A. Matveev, Pet. Chem. 54, 686 (2014).

204. G. G. Kagramanov and E. N. Farnosova, Pet. Chem. 52, 625 (2012).

205. R. M. Gould, S. L. White, and C. R. Wildemuth, Environ. Prog. 20, 12 (2001).

206. P. Vandezande, L. E. M. Gevers, and I. F. J. Vankelecom, Chem. Soc. Rev. 37, 365 (2008).

207. A. V. Volkov, G. A. Korneeva, and G. F. Tereshchenko, Russ. Chem. Rev. 77, 983 (2008).

208. P. Marchetti, M. F. Jimenez Solomon, G. Szekely, and A. G. Livingston, Chem. Rev. 114, 10735 (2014).

209. K. Vanherck, G. Koeckelberghs, and I. F. Vankelecom, Prog. Polym. Sci. 38, 874 (2013).

210. A. A. Tashvigh, L. Luo, T. S. Chung, et al., J. Membr. Sci. 545, 221 (2018).

211. A. A. Yushkin, M. N. Efimov, A. A. Vasilev, et al., Pet. Chem. 57, 341 (2017)

212. S. Tsarkov, V. Khotimsky, P. M. Budd, et al., J. Membr. Sci. 423-424, 65 (2012).

213. M. Amirilargani, M. Sadrzadeh, E. J. R. Sudholter, and L. C. P. M. de Smet, Chem. Eng. J. 289, 562 (2016).

214. P. S. Goh and A. F. Ismail, Desalination 434, 60 (2018).

Translated by E. Boltukhina 